\title{
Gamificação: uma metodologia ativa e inclusiva no \\ processo de ensino-aprendizagem
}

\section{Gamification: an active and inclusive methodology in the teaching-learning process}

\author{
Márcia Cristina Nunes Avansi ${ }^{1}$ \\ Simone Ferreira ${ }^{2}$ \\ Leise Ruth Lima de Oliveira Ascencio ${ }^{3}$ \\ Rosemyriam Cunha ${ }^{4}$ \\ Noemi Nascimento Ansay ${ }^{5}$
}

\begin{abstract}
Resumo: Este trabalho tem por objetivo discorrer sobre a importância das metodologias ativas, dentre elas a gamificação, uma estratégia de ensino emergente no contexto atual que utiliza elementos presentes nos jogos/games em contextos de não jogos. A qual pode motivar e engajar todos os estudantes na realização das atividades dos diferentes conteúdos curriculares. O problema que norteou este estudo foi identificar se as metodologias ativas podem contribuir no processo de ensino-aprendizagem dos estudantes público alvo da educação especial. $\mathrm{O}$ estudo englobou a pesquisa bibliográfica de caráter qualitativa e os resultados indicaram que as metodologias ativas, especialmente a gamificação pode desenvolver a motivação, engajamento, colaboração, criticidade, autonomia e o protagonismo dos estudantes por meio de práticas inclusivas que beneficiam a todos, com ou sem deficiência.
\end{abstract}

Palavras-chave: Metodologias ativas; Gamificação; Alunos com deficiência; Práticas inclusivas.

\footnotetext{
${ }^{1}$ Mestranda do Mestrado Profissional em Educação inclusiva-PROFEI, UNESPAR, mcrisnunesavansi@gmail.com

${ }^{2}$ Mestranda do Mestrado Profissional em Educação inclusiva-PROFEI, UNESPAR, ferreirasimonep@ hotmail.com

${ }^{3}$ Mestranda do Mestrado Profissional em Educação inclusiva-PROFEI, UNESPAR, leise.ruth@ hotmail.com

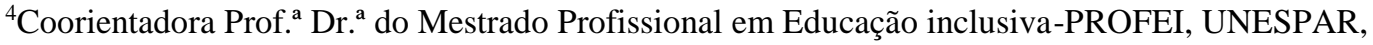
rosemyriam.cunha@unespar.ed.br

${ }^{5}$ Orientadora Prof. ${ }^{\text {a }}$ Dr. ${ }^{\text {a }}$ do Mestrado Profissional em Educação inclusiva-PROFEI, UNESPAR, noemi.ansay@ies.unespar.edu.br
}

Recebido em 23/01/2022

Aprovado em 10/02/2022

Sistema de Avaliação: Double Blind Review

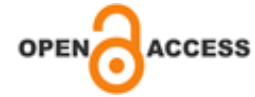




\section{REVISTAMULTDIISCPLLIAR \\ ISSN 1809-1628

Abstract: This work aims to discuss the importance of active methodologies, including gamification, an emerging teaching strategy in the current context that uses elements present in games/games in non-game contexts. Which can motivate and engage all students in carrying out the activities of the different curricular contents. The problem that guided this study was to identify whether active methodologies can contribute to the teaching-learning process of students who are the target audience of special education. The study included bibliographic research of a qualitative nature, the results indicated that active methodologies, gamification can develop motivation, engagement, collaboration, criticality, autonomy and the protagonism of students through inclusive practices that benefit students with or without disabilities.

Keywords: Active methodologies; Gamification; Students with disabilities; Inclusive practices.

\section{Introdução}

O processo de inclusão exige de todos na escola: professores, equipe pedagógica, funcionários, família e estudantes um trabalho colaborativo que possa beneficiar a todos, respeitando o ritmo de aprendizagem de cada um, onde o foco seja as potencialidades e não as dificuldades dos estudantes. O que demanda do educador propor práticas de ensino inclusivas pensadas em função de como os estudantes Público Alvo da Educação Especial (PAEE) aprendem. Neste contexto, as metodologias ativas de ensino podem favorecer o processo de ensino-aprendizagem, tornando os estudantes protagonistas do seu processo de aprendizagem.

As metodologias ativas, dentre elas a gamificação, podem favorecer as práticas pedagógicas inclusivas, com ou sem recursos tecnológicos. As quais podem contribuir no protagonismo dos estudantes por meio da interação com seus pares, momento em que pesquisam, discutem, apresentam suas ideias para os demais. Na realização das atividades todos ficam motivados e engajados, tendo em vista que são responsáveis pela realização de cada etapa, sendo o professor o mediador entre os estudantes e o conteúdo. A gamificação pode contribuir para que os estudantes fiquem motivados e engajados por enfatizar elementos presentes nos jogos/games em contextos educativos para trabalhar com diferentes conteúdos curriculares (MORAN, 2018).

Neste sentido, situa-se o problema de pesquisa abordando: como as metodologias ativas podem contribuir no processo de ensino-aprendizagem dos estudantes PAEE? O objetivo consiste em discorrer sobre a importância das metodologias ativas, dentre elas a gamificação no processo de ensino-aprendizagem dos estudantes PAEE. Para isso, o estudo 


\section{REVISTAMULTDIISCPLLIAR \\ ISSN 1809-1628

utiliza a abordagem qualitativa e pesquisa bibliográfica, por meio da leitura de artigos, dissertações e teses, cujas temáticas estejam relacionadas ao objeto deste artigo, quais sejam as metodologias ativas como práticas inclusivas no processo de aprendizagem dos estudantes PAEE.

\section{Educação inclusiva}

No decorrer da história, as pessoas com deficiência sofreram preconceitos sendo segregadas por não se enquadrarem nos parâmetros de normalidade impostos pelas sociedades. Assim, a educação das pessoas com deficiência foi marcada por um cenário excludente, vigorando o paradigma da institucionalização, em que as pessoas com deficiência eram segregadas em instituições para tratamento médico. Depois, o paradigma de serviços, em que o atendimento tinha enfoque clínico terapêutico, para a reabilitação das pessoas com deficiência, com o objetivo de tornar as pessoas o quanto possível dentro do padrão de normalidade das sociedades vigentes. Por último o paradigma de suportes a nível social, econômico, físico e instrumental, em que a pessoa com deficiência passa a ser respeitada nas suas diferenças, tendo garantido o direito à inclusão educacional e social (FERNANDES; SCHLESENER; MOSQUEIRA, 2011).

A partir do século XX, inicia-se um período em que a pessoa com deficiência passa a ser vista nos seus direitos perante as diferenças. "O século $\mathrm{XX}$ foi marcado por mudanças de paradigmas. Ele trouxe consigo avanços importantes para os indivíduos com deficiência, sobretudo em relação às ajudas técnicas" (FERNANDES; SCHLESENER; MOSQUEIRA, 2011, p.139).

De acordo com a Resolução CNE/CEB n ${ }^{\circ}$ 2/2001 artigo 2º "os sistemas de ensino devem matricular todos os alunos, cabendo às escolas organizarem-se". O que condiz com a Declaração de Salamanca, (1994), no artigo 7: “o princípio fundamental da escola inclusiva é o de que todas as crianças devem aprender juntas, sempre que possível independentemente de quaisquer dificuldades que elas possam ter". Contudo, o Decreto 10.502/2020 trouxe um desalento ao apontar um possível retrocesso.

Outro marco importante é a Lei de Diretrizes e Bases da Educação Nacional - Lei no 9.394/96, no artigo 59, que preconiza que os sistemas de ensino devem assegurar aos alunos currículo, métodos, recursos e organização específicos para atender às suas necessidades. 


\section{REVISTAMULTDISCPLLINAR \\ ISSN 1809-1628

A Política Nacional de Educação Especial na Perspectiva da Educação Inclusiva (2008), preconiza que a inclusão é um movimento mundial em defesa do direito de todos os alunos aprenderem juntos em todos os níveis, etapas e modalidades de ensino, sendo garantido para o público da educação especial, atendimento educacional especializado, conforme as especificidades de cada aluno.

Estes direitos ao serem valorizados garantem a todos os alunos a equidade nas diferenças. Negar o lugar comum de aprendizagem aos estudantes com deficiência seria retomar paradigmas de exclusão escolar e social. Como pontua Vygotsky (1997), a deficiência do indivíduo segue uma ordem primária, um defeito, englobando os problemas orgânicos, e uma secundária, decorrente das causas psicossociais, esta é a mais complexa, ocorrendo em função de um padrão estigmatizante acerca da normalidade, criando barreiras físicas, educacionais e atitudinais para a participação social e cultural da pessoa com deficiência. Pois, não são os ditos defeitos que interferem no desenvolvimento, mas, sim, o que provém da falta de interação social.

De acordo com Hostins e Jordão (2014) o século XXI aborda a política de inclusão a nível nacional e internacional a respeito dos direitos constitucionais das pessoas com deficiência, transtornos globais do desenvolvimento e altas habilidades. A Lei de Diretrizes e Bases da Educação Nacional - LDBEN nº. 9394/96 enfatiza que estas pessoas, público da educação especial, devem aprender preferencialmente no ensino regular com todos os serviços e suportes necessários para efetivarem seu processo de aprendizagem, juntamente com os demais alunos. Dentre esses serviços, apresenta-se o Atendimento Educacional Especializado (AEE).

$\mathrm{O}$ atendimento educacional especializado contempla um trabalho colaborativo entre professor especialista com o comum, tendo em vista planejar, analisar a respeito das melhores estratégias, recursos de ensino e avaliação para que todos os estudantes sintam-se pertencentes no espaço educativo e participem de todas as atividades (BRASIL, 2008). Na sala de recursos multifuncional (SRM) ou o professor de apoio é necessário: “[...] criar situações que exijam a observação, o registro e análise para a aprendizagem de todos os alunos, notadamente da SRM, que podem, desse modo, manifestar sob diferentes maneiras e mediante o uso de estratégias diversificadas, sua capacidade de aprender" (HOSTINS; JORDÃO, 2014, p.13).

Assim, a escola inclusiva precisa ser de qualidade para todos os alunos, portanto, seu papel centra-se em efetivar estratégias de ensino para que todos tenham uma permanência 


\section{REVISTAMULTDISCIPLINAR \\ ISSN 1809-1628 HUMANIDADES E TECNOLOGIAS (FINOM)}

com sucesso, tendo condições para um desenvolvimento integral, sendo o foco do processo de ensino-aprendizagem as potencialidades e não as limitações.

Isto posto é de fundamental importância o papel do educador enquanto mediador de todo o processo de aprendizagem, uma vez que os direitos de cada pessoa e a educação só se efetivam à medida que há um ensino significativo e contextualizado para todos. Uma educação focada nas questões afetivas, cognitivas, psicomotoras e socializadoras, em que as estratégias de ensino possam oportunizar a sistematização dos saberes de todos os alunos. Nesse contexto, se faz necessário que o educador ressignifique o como ensinar, tendo em vista atingir as necessidades específicas dos alunos no que diz respeito ao como aprendem, tendo em vista que, há demandas para que os educadores incorporem as metodologias ativas no processo de ensino-aprendizagem as quais podem contribuir no desenvolvimento do protagonismo dos alunos.

\section{Metodologias ativas}

As metodologias ativas são estratégias de ensino que permitem que os alunos sejam protagonistas no seu processo de aprendizagem a partir da pesquisa, trabalho em equipe, na realização de atividades por instruções, sequências gamificadas, dentre outras possibilidades (MORAN, 2018). Outro fator importante é que por meio das metodologias ativas é possível efetivar o ensino colaborativo que garanta os direitos humanos, a diversidade e a equidade, haja visto que, o professor da educação especial em parceria com o professor do ensino comum repensam juntos, os objetivos de ensino que o aluno precisa dominar para determinada série. Neste contexto decidem sobre as metodologias, recursos de ensino e a avaliação para que os alunos com deficiência possam ter acesso ao currículo Dessa forma, todos os demais independentemente de terem ou não diagnóstico de deficiência possam se beneficiar das práticas de ensino inclusiva (MARIN; BRAUN, 2013).

De acordo com Mendes e Silva (2014, p.2) isso remete para a importância do currículo como: um território organizado por meio de normativas, de orientações, de interesses profissionais e de aprendizagens, na base dos pressupostos da globalidade da ação educativa, da diferenciação/flexibilidade curricular e da integração das atividades educativas. Nesse sentido, nos remete, também, à constatação de que o debate sobre qual conhecimento deve ser "ensinado" na escola, é a todo tempo retomado pelos contextos, práticas, sujeitos e políticas, e 


\section{REVISTAMULTDISCPLINAR \\ ISSN 1809-1628

pelas demandas próprias da contemporaneidade para atender as especificidades dos alunos PAEE.

Um currículo contextualizado, aberto e flexível pensado para atender todos os estudantes, que integre práticas inovadoras de ensino, atrelado às tecnologias digitais de informação e comunicação (TDIC). Capaz de atender as aspirações dos estudantes que são como salienta Prensky (2010) apud Mendes e Silva (2014) "nativos digitais”, uma geração que tem muita facilidade para utilizar os recursos tecnológicos. O que exige dos educadores formação continuada para fazerem a mediação docente, associando com a tecnologia, propondo metodologias ativas de ensino para engajar todos os estudantes na realização das atividades.

As metodologias são grandes diretrizes que orientam os processos de ensino e aprendizagem e que se concretizam em estratégias, abordagens e técnicas concretas, específicas e diferenciadas. Metodologias ativas são estratégias de ensino centradas na participação efetiva dos estudantes na construção do processo de aprendizagem, de forma flexível, interligada e híbrida. A metodologia ativa se caracteriza pela inter-relação entre educação, cultura, sociedade, política e escola, sendo desenvolvida por meio de métodos ativos e criativos, centrados na atividade do aluno com a intenção de propiciar a aprendizagem (MORAN, 2018).

A variedade de estratégias metodológicas a serem utilizadas no planejamento das aulas é um recurso importante, por estimular a reflexão sobre outras questões essenciais, como a relevância da utilização das metodologias ativas para favorecer o engajamento dos alunos e as possibilidades de integração dessas propostas ao currículo. É certo que as pessoas não aprendem da mesma forma, no mesmo ritmo e ao mesmo tempo. Inserir as tecnologias digitais, por meio de metodologias ativas, de forma integrada ao currículo escolar requer uma reflexão sobre alguns componentes fundamentais desse processo e, entre eles, o papel do professor e dos estudantes em uma proposta de condução da atividade didática que privilegia as metodologias ativas.

O que constatamos, cada vez mais, é que a aprendizagem por meio da transmissão é importante, mas a aprendizagem por questionamento e experimentação é mais relevante para uma compreensão mais ampla e profunda.

A ênfase na palavra ativa precisa sempre estar associada à aprendizagem reflexiva, para tornar visíveis os processos, os conhecimentos e as competências do que estamos 


\section{REVISTAMULTDISCPLINAR \\ ISSN 1809-1628

aprendendo com cada atividade. Ensinar e aprender tornam-se fascinantes quando se convertem em processos de pesquisa constantes, de questionamento, de criação, de experimentação, de reflexão e de compartilhamento crescentes, em áreas de conhecimento mais amplas e em níveis cada vez mais profundos.

As metodologias ativas dão ênfase ao papel protagonista do aluno, ao seu envolvimento direto, participativo e reflexivo em todas as etapas do processo, experimentando, desenhando, criando, com orientação do professor, dentre as metodologias ativas existe a gamificação.

\section{Gamificação}

A gamificação é uma metodologia ativa que permite utilizar elementos presentes nos jogos em contextos de não jogos com objetivos de ensino definidos. $\mathrm{O}$ educador é o mediador do processo de ensino aprendizagem entre aluno-conteúdo-realidade social, portanto precisa aliar com competência teoria e prática. Momento em que mobiliza no seu fazer docente conceitos a respeito do processo de ensino-aprendizagem, então, realiza um planejamento, tendo em vista quem são os estudantes e de que forma todos podem aprender os conteúdos (LIBÂNEO, 2015). Considerando-se a prática pedagógica numa dimensão inclusiva cabe ao educador rever suas estratégias de ensino para que atendam às necessidades específicas de todos os estudantes. Como pontua Mantoan (2015, p.76):

\footnotetext{
As escolas inclusivas atendem a todos os alunos sem discriminar, sem trabalhar à parte com alguns deles, sem estabelecer regras específicas para planejar, ensinar e avaliar alguns por meio de currículos adaptados, atividades diferenciadas, avaliação simplificada em seus objetivos.
}

Em vista disso, é preciso repensar numa prática pedagógica que seja capaz de engajar todos os estudantes no mesmo propósito da atividade, oportunizando a interação e o fazer colaborativo e cooperativo entre eles. De acordo com Marin e Braun (2013) a adequação pedagógica, ou seja, os ajustes beneficiam a todos os estudantes, podendo ser na objetividade do enunciado, uso de imagens, trabalhos em grupo, jogos pedagógicos, plataformas com atividades gamificadas e recursos de ensino concreto para melhor exemplificar o conteúdo. $\mathrm{Na}$ forma de avaliar: oral, desenho, exposição em grupo, pesquisa, resumo, entrevista, relato, dentre outras.

As estratégias precisam ser pensadas para todos os estudantes. O que exige repensar o como planejar para que todos os estudantes tenham acesso ao currículo. Já que, não são os 


\title{
REVISTAMULTDISCPLINAR \\ ISSN 1809-1628 HUMANIDADES E TECNOLOGIAS (FINOM)
}

estudantes que se adaptam à escola, mas esta que prevê e provê os meios, para que tenham acesso e permanência com sucesso junto aos demais estudantes. Estas ponderações segundo Moreira; Amorim; Soares, (2020. p.99) mostram que: “[...] o professor, reflexivo diante de suas práticas pedagógicas, pode procurar metodologias de ensino que melhor explorem em seus alunos o seu desenvolvimento de forma dialógica". E que a gamificação pode ser uma destas metodologias, já que existe uma relação entre gamificação e a educação, a intervenção didática com atividade gamificada pode ser uma forma viável para motivar e ampliar a cooperação entre os estudantes no desenvolvimento das atividades referente aos diferentes conteúdos curriculares. A gamificação por atrelar elementos dos jogos amplia o envolvimento dos alunos nas diferentes atividades, portanto, pode trazer benefícios motivacionais ao despertar o interesse em alcançar um resultado superior ao anterior, a cooperação e o trabalho em grupo por meio de uma competição saudável (MOREIRA; AMORIM; SOARES, 2020).

\begin{abstract}
Para que a atividade seja interessante para o aluno este deverá estar dotado de motivação para cumpri-la, ser capaz de resolver a questão e ao mesmo tempo, através de um gatilho, ser levado a desempenhar determinada ação. A partir do momento que este está inserido em um meio social e outras pessoas também dependem do trabalho dele e um objetivo bem desenhado está posto ele será instigado a terminar a ação. Seja por uma maior aceitação pela sua equipe, por uma insígnia de condecoração que irá reconhecer seu trabalho ou até por cumprir a tarefa e ter seu "nível" alterado, uma das formas interessantes de se trabalhar a gamificação é a construção de níveis de reconhecimento onde o participante à medida que cumpre determinadas tarefas ou acumula "experiência" é reconhecido e tem seu nível aumentado (MOREIRA; AMORIM; SOARES, 2020, p.101).
\end{abstract}

Assim sendo, a gamificação contribui tanto para o desenvolvimento individual, quanto coletivo dos alunos, o diálogo, a crítica, às descobertas contribuem para a aprendizagem de todos. Por isso, precisa ser planejada a partir de um roteiro e de uma sequência lógica de atividades que permitam a motivação, engajamento dos alunos durante todo o processo de ensino-aprendizagem (MOREIRA; AMORIM; SOARES, 2020).

Autores como Silva; Sales; Castro (2019) e Martins; Giraffa (2018), destacam que de fato a gamificação mostra-se como uma tendência promissora, que consiste na utilização de elementos dos jogos digitais em atividades de não jogos, tanto para engajar, motivar, quanto para melhorar o desempenho dos alunos no processo de aprendizagem dos diferentes conteúdos, “[...] não significa criar um jogo de viés pedagógico ou simplesmente jogar para ensinar. Vai além: é preciso compreender e significar mecânicas e dinâmicas presentes em jogos digitais permeando-os em práticas pedagógicas" (MARTINS; GIRAFFA, 2018, p.7). 


\section{REVISTAMULTDISCPLINAR \\ ISSN 1809-1628

As tecnologias Digitais de Informação e Comunicação (TDIC) representam um meio eficaz para despertar o interesse dos alunos da contemporaneidade, atreladas às metodologias ativas, dentre elas a gamificação. A atividade gamificada aplicada como estratégia de aprendizagem pode ter uma influência significativa, quando comparada à metodologia tradicional. Conforme Martins; Giraffa (2018), os professores quando ficam presos em práticas pedagógicas tradicionais e desconsideram a cibercultura, tornam o ensino fragmentado e descontextualizado, deixa de atender as necessidades de aprendizagens exigidas na atualidade permeada por uma geração que vive na era digital.

\footnotetext{
Esse é um dos motivos pelo qual a gamificação retorna à pauta das possibilidades educacionais, adotando aproximações relevantes e com potencial pedagógico dos comportamentos dos estudantes relacionados aos jogos digitais. $\mathrm{O}$ mote principal da gamificação seria auxiliar na motivação do estudante a aprender e construir seu conhecimento. Considerando os princípios construtivistas, de cunho sociointeracionista, a motivação e a interação social com os outros e com o meio cultural constituem fatores prementes para a aprendizagem (MARTINS; GIRAFFA, 2018, p.10).
}

Neste viés, entendemos a Gamificação como uma metodologia ativa que pode ser eficaz no cenário educacional vigente por possibilitar a todos os estudantes, incluindo os PAEE, protagonismo e autonomia na realização de atividades desafiadoras, desenvolvendo assim um aprendizado mais significativo e consolidado.

\section{Considerações finais}

Com base na pesquisa realizada podemos dizer que a sociedade atual vivencia uma cultura de inclusão. Antes era exigido que as pessoas com deficiência se adequassem a sociedade, agora cabe a sociedade como um todo adequar-se para atender as peculiaridades destas pessoas. O que fica evidente que, cabe ao profissional de educação, valorizar as potencialidades dos estudantes com deficiência buscando metodologias diferenciadas, capazes de engajar e motivar estes para realizarem todas as atividades propostas na interação com o outro.

Nesse viés, a escola pública precisa de políticas públicas que repassem mais recursos financeiros, propiciando condições de trabalho e, que haja investimento na formação de professores, para que com isso, todos os educadores possam estar mais preparados para trabalharem com os estudantes com deficiências, mediante uma mediação centrada no processo de ensino e aprendizagem, visando sempre o pertencimento dos estudantes e o desenvolvimento das suas potencialidades. Portanto, possa estar inovando o como ensinar 


\section{जave

para que todos os alunos possam interagir entre si e com o objeto de estudo, contribuindo na construção da sua aprendizagem de forma mais lúdica e prazerosa.

Deste modo, consideramos que os objetivos foram alcançados, pois a partir da transformação na metodologia e recursos de ensino todos os alunos podem desenvolver suas potencialidades motoras e a interação social. Assim sendo, quando o docente redimensiona seus objetivos, métodos, recursos de ensino e a avaliação, corrobora para que haja uma inclusão de qualidade para todos os alunos, independentemente das suas singularidades.

\section{Referências}

ALVES, Flora. Gamification - como criar experiências de aprendizagem engajadoras. Um guia completo: do conceito à prática. $2^{\mathrm{a}}$ ed. São Paulo: DVS, 2015.

BRASIL. Ministério da Educação/SEESP. Política Nacional de Educação Especial na Perspectiva da Educação Inclusiva. Brasília, MEC/SEESP, 2008.

BRASIL. Ministério da Educação. Secretaria de Educação Especial. Institui Diretrizes Operacionais para o Atendimento Educacional Especializado na Educação Básica, modalidade Educação Especial. RESOLUÇÃO No 4, DE 2 DE OUTUBRO DE 2009.

BRASIL. Lei $\mathrm{n}^{\text {o }}$ 13.146, de 6 de julho de 2015. Institui a Lei Brasileira de Inclusão da Pessoa com Deficiência (Estatuto da Pessoa com Deficiência).

BRASIL. DECRETO No 10.502, DE 30 DE SETEMBRO DE 2020. Institui a Política Nacional de Educação Especial: Equitativa, Inclusiva e com Aprendizado ao Longo da Vida.

BRASIL. Ministério da Educação. Secretaria de Modalidades Especializadas de Educação. PNEE: Política Nacional de Educação Especial: Equitativa, Inclusiva e com Aprendizado ao Longo da Vida. Brasília; MEC. SEMESP. 2020. 124p.

BRASIL. Ministério da Educação. Política nacional de Educação Especial na perspectiva da educação inclusiva. Brasília: MEC, 2008.

BRASIL. Ministério da Educação/ Conselho Nacional de Educação. Resolução CNE/CB no 04/2009. Diretrizes Nacionais Gerais para Educação Básica. Conselho Nacional de Educação. Brasília: MEC/CNE, 2009.

BRASIL. Ministério da Educação. Decreto $\mathbf{N}^{\circ}$ 7.611, de 17 de novembro de 2011. Diário Oficial da União. Edição extra. BRASIL: 18 de novembro de 2011.

BRASIL. Ministério da Educação. Conselho Nacional de Educação. Diretrizes Nacionais para a Educação Especial na Educação Básica. Parecer CNE/CEB n.2, DE 11 DE SETEMBRO DE 2001. 
BRASIL. Declaração de Salamanca e Linha de Ação sobre necessidades Educativas Especiais. Brasília: CORDE, 1994.

BRASIL. Ministério da Educação/SEESP. Política Nacional de Educação Especial na Perspectiva da Educação Inclusiva. Brasília, MEC/SEESP, 2008.

BRASIL. Lei de diretrizes e bases da educação nacional n 9394/1996. Brasília: Senado Federal, Coordenação de Edições Técnicas, 2017. Disponível em: https://www2.senado.leg.br/bdsf/lei_de_diretrizes_e_bases_1ed.pdf. Acesso em: 29 de jul. de 2020.

BRASIL. Ministério da Educação. Base Nacional Comum Curricular. Brasília: MEC, SEB, 2017.

http://www.educadores.diaadia.pr.gov.br/referencial_curricular_parana_cee.pdf. Acesso em: 25 de nov. de 2021.

BRASIL. Lei $\mathrm{n}^{\mathrm{o}}$ 13.146, de 6 de julho de 2015. Institui a Lei Brasileira de Inclusão da pessoa com Deficiência (Estatuto da Pessoa com Deficiência). Brasília, 2015. Disponível em: http://www.planalto.gov.br/ccivil_03/_ato2015-2018/2015/lei/113146.htm. Acesso em: 27 de nov. de 2021.

BRASIL. Convenção de Guatemala. Eliminação de todas as formas de discriminação contra as pessoas portadoras de deficiência. Brasília, 2001.

BRASIL. Estatuto da Criança e do Adolescente. Lei 8069/90. Brasília, 1990.

BRASIL. Constituição Federal - 1988. Brasília: Câmara dos Deputados, 1994.

FERNANDES, Lorena Barolo, SCHLESENER, Anita; MOSQUERA, Carlos. Breve histórico da deficiência e seus paradigmas. Revista do Núcleo de Estudos e Pesquisa Interdisciplinares em Musicoterapia, Curitiba, v.2, p.132-144, 2011.

HOSTINS, R. C. L., JORDÃO, S. G. F. Política de inclusão escolar e práticas curriculares de elaboração conceitual de alunos público-alvo da Educação Especial. Arquivos Analíticos de Políticas Educativas, Arizona, Estados Unidos, v. 23, n. 28, 2014.

LIBÂNEO, J. C. Formação de Professores e Didática para Desenvolvimento Humano. Educação \& Realidade, Porto Alegre, v.40, n.2, p. 629-650.

MANTOAN, M. T. E. Inclusão escolar- O que é? Por quê? Como Fazer?.1 ${ }^{\circ}$ ed. Rio de Janeiro: Sindicato Nacional dos Editores de Livros, 2015.

MARIN, M.; BRAUN, P. Ensino colaborativo como prática de inclusão escolar. In: GLAT, R.; PLETSCH, M. D. (Org.). Estratégias educacionais diferenciadas para alunos com necessidades especiais. Rio de Janeiro: EdUERJ, 2013, p. 49-64. 


\section{REVISTA MULTIDISCIPLINAR \\ ISSN 1809-1628 HUMANIDADES ETECNOLOGIAS (FINOM)}

MARTINS, Cristina; GIRAFFA, Lucia Maria Martins. Possibilidades de ressignificações nas práticas pedagógicas emergentes da gamificação ETD-Educação Temática Digital. Campinas, SP. v. 20, n.1, p. 5-26, jan./mar, 2018.

MENDES, G. M. L; SILVA, F. C. T. Currículo e conhecimento escolar na contemporaneidade: desafios para a escolarização de sujeitos com deficiência. Arquivos Analíticos de Políticas Educativas, Arizona, Estados Unidos, v. 22, n. 80, p. 1-19, ago. 2014.

MONTANARO, Paulo Roberto. Gamificação para a Educação. INOVAEH UFSCar/ SEaD. São Carlos, 2018.

MORAN, J. Metodologias ativas para uma aprendizagem profunda. In: MORAN, J; BACICH, L. (Org.). Metodologias ativas para uma educação inovadora: uma abordagem teórico-prática. Porto Alegre: Penso, 2018.

MORAN, J. M. Mudando a educação com metodologias ativas. In Convergências Midiáticas, Educação e Cidadania: aproximações jovens. Coleção Mídias Contemporâneas. 2015.

Disponível

em http://www2.eca.usp.br/moran/wpcontent/uploads/2013/12/mudando_moran.pdf. Acesso em: 24/11/21.

MORAN, José. (Org) Metodologias ativas para uma aprendizagem mais profunda. In: BACICH, Lilian; MORAN, José. (Orgs). Metodologias ativas para uma educação inovadora: uma abordagem téorico-prática [recurso eletrônico]. Porto Alegre: Penso, 2018. p.34-76.

MOREIRA, Tiago Bacciotti; AMORIM, Alvino Moraes de; SOARES, Natal dos Santos. Experimento didático-pedagógico: um caminho para a investigação da gamificação na educação. In: SILVA, Américo Junior Nunes da; SOUZA, Ilvanete dos Santos de; LIMA, Reinaldo Feio. Organizadores. Educação e a apropriação e reconstrução do conhecimento científico. Ponta Grossa - PR: Atena, 2020.p.98-105.

Silva, J. B., \& Sales, G. L. Gamificação aplicada no ensino de Física: um estudo de caso no ensino de óptica geométrica. Acta Scientiae, 19(5), 2017.

TOLOMEI, Bianca Vargas. A Gamificação como Estratégia de Engajamento e Motivação na Educação. Revista científica EAD em Foco. v.7, n.2, p. 145-156, 2017. Disponível em: https://eademfoco.cecierj.edu.br/index.php/Revista/article/view/440. Acesso em: 27 de nov.. 2021.

VYGOTSKY, L.S. Los problemas fundamentales de la defectologia contemporánea. Fundamentos da Defectologia. Obras Escogidas V. Madrid: Visor, 1997, p. 11-40. 